\title{
Studying Documentation
}

Daniel Shine, MD*

Department of Medicine, New York University Langone Medical Center, New York, New York.

In 1968, Weed highlighted the importance of medical documentation when he proposed a single format for notes. ${ }^{1,2}$ Since then, sweeping changes in the technology, the purposes, and the requirements of clinical record keeping have encouraged steady growth of a literature devoted to the chart. Specifically, over the past half century, computers, lawsuits, regulations, and the use of documentation as a tool of billing have all contributed to the transformation of hospital records. In addition, mounting pressure to shorten inpatient stays, the vastly increased complexity of care, and a growing number of diagnostic possibilities have combined to make medical documentation far more prolific and far less leisurely. All these changes have stimulated a boom in documentation research coinciding, productively, with an era of rapid advances in the conduct of clinical trials and statistical rigor. However, in important respects research into medical documentation today is not asking the right questions, either in the formulation of hypotheses or in the choice of methodology. Forms of clinical communication that do not involve order sets or notes are widespread, growing in sophistication, and increasingly relevant to new concepts of healthcare as a team enterprise; but documentation research has not embraced this development. At the same time, methodologically, the field suffers from a persistent professional bias in the choice of research outcomes, a bias that limits the interpretation of results by neglecting what happens to the patient.

In assessing the chart as a communication device and the effect of changes in documentation, it is increasingly necessary to study direct interpersonal communication as an alternative and partner to writing notes. In particular, 3 recent developments in healthcare emphasize the importance of broadening our concepts of clinical communication. First, the need for discussion in the medical record has become less pressing because of technical improvements in person-to-person communication. Second,

*Address for correspondence and reprint requests: Daniel Shine, MD, Department of Medicine, NYU Langone Medical Center, 550 First Avenue, New York, NY 10016; Telephone: 917-855-5309; Fax: 732-345-9340; E-mail: daniel.shine@nyumc.org

Additional Supporting Information may be found in the online version of this article.

Received: September 23, 2013; Revised: October 1, 2013; Accepted: October 2, 2013

2013 Society of Hospital Medicine DOI 10.1002/jhm.2104

Published online in Wiley Online Library (Wileyonlinelibrary.com). the electronic health record, by creating disciplinedefined "chart views," has helped equalize the stature of different healthcare disciplines but also Balkanized the chart, making direct interdisciplinary communication more necessary. Third, changes in reimbursement are redefining medical goals in such a way that only teams of healthcare providers in close and constant personal communication can achieve them.

Rapid adoption of electronic health records has encouraged researchers studying documentation or information technology to focus on computer formats as defining the range of all possible communication strategies. And certainly there is a broad range of formats: electronic progress notes may be free text or multiple choice, typed or dictated, copy forwarded or composed daily, institutionally templated or selftemplated, furnished with or free from prompts and pop-ups. However, it is not only, and perhaps not even principally, the electronic record that has changed how clinicians communicate with each other. The technology of discussion over the last 2 decades has become instant, utterly mobile, device independent, and capable of connecting all the patient's caregivers at once to each other and to the medical record in text, picture, and sound. That the same communications upheaval has visited practically every other aspect of our lives diminishes perhaps the visibility of this new virtual team in healthcare but not its importance.

The electronic record certainly plays a role in facilitating communication, through simultaneous chart access and in many other ways, but even more significant is the effect that computerization has had on equalizing the roles of different disciplines and by doing so in fragmenting the medical record. A computerized record expands and reorganizes "the chart," changing it from a single authoritative book read by all to an almost limitless array of "chart views," each read by some. All viewers (patient, clinician or researcher, administrator, reviewer or coder) can, with equal claim to consulting the chart, categorize, compare, combine, and format data elements from 1 or many encounters, whether inpatient or ambulatory. Typically, an electronic item of patient information may have several authors and uses but has no owner. Data are entered by protocol and in different guises into many aspects of patient care as components of notes, flow sheets, summaries, pop-ups, and order sets unique to each of a number 
of disciplines. As the electronic record equalizes but also separates members of the healthcare team, interdisciplinary personal communication becomes more, not less, important.

Recent and impending reimbursement reform proves also to be a means of democratizing medical care and enforcing better interdisciplinary communication. The basis for hospital reimbursement has evolved over decades from day rates to payments for specific diseases, a system under which profit margins are in theory determined by the interdisciplinary efficiency with which diseases are managed by all care givers and the accuracy with which that management is documented. The next, seemingly inexorable, step in the evolution of reimbursement will result in further democratization of care givers: a single combined "disease episode" payment will be divided among all those involved in a course of treatment that may span many months and require many disciplines and many types of intervention. Payment reform makes the success of a visiting nurse as important to the net reimbursement of a disease episode as the success of an orthopedic surgeon; for if the visiting nurse does not do well the patient will be readmitted or require more office services. In this sense, payment reform, like the electronic record, tends both to equalize the importance of different healthcare roles and to require their enhanced communication.

As these changes in technology and reimbursement evolve, the study of medical documentation must increasingly address medical communication more generally. It is entirely possible, for example, that an individual daily progress note, whose preparation consumes so many hours and removes caretakers from patients, will no longer serve any demonstrable purpose. ${ }^{3,4}$ It may be that consensus summaries will prove more useful in clarifying one's own thinking and incorporating that of others than will a daily, solo chart soliloquy in free or imported text. It is conceivable that contrasting views will be best presented not as a debate in the progress notes but as a plan mutually agreed upon earlier in the decision-making process. These are the kind of broader questions that investigators in medical documentation should be pursuing.

Another problem in studies of documentation is a pervasive professional bias in the choice of end points. Studies tend to evaluate documentary practices not by their effect on patients but by their impact on physicians or nurses. Success is measured by clinician satisfaction, percent adoption, and note length or timing; note quality is judged using a checklist derived from professional surveys. ${ }^{5-15}$ End points like these will often make 1 document look better than another in a "results" section, but it is the relation between communication strategies and healthcare outcomes that determines whether 1 approach or another is of benefit to the patient.
For example, an important current debate is whether free text adds essential nuance to a note or is simply nostalgia, a relic of the 3-ring binder. ${ }^{16-18}$ This debate can be resolved convincingly only if improvement with the use or abolition of free text is measured in terms of patient outcomes or resource consumption. Again, if it is important to know whether progress notes of a particular length or structure create less handover confusion, then changes in medical error rates is a more persuasive way to evaluate this issue than a change in physician opinion. It may be a good question whether briefer notes will free nurses and doctors to spend more time at the bedside, but along with recording bedside time that study should also measure improvement in reacting to important changes of clinical status. With today's technology, group phone discussions could perhaps successfully replace examining each other's notes, but the measure of success should be improved hospital efficiency or a decline in errors and readmissions.

The questions we ask in our research today create the treatments and policies of tomorrow. Our studies must address communications in a larger sense, must encompass all the settings in which an "episode of care" occurs, and must focus on patient outcomes and use of resources. The measured end points of an intervention should of course be sensitive to the particular setting where the intervention takes place, or else small and location-specific gains will be missed. However, real health effects and robust measures of efficiency must take the place of word counts, inclusion checklists, and clinician adoption or satisfaction in the design of documentation studies.

A great national experiment is underway involving the deployment of information technology, the expansion and empowerment of healthcare teams, and the retargeting of economic incentives. The experimental hypothesis is that technology will increase medical efficiency and will benefit patient well-being only if these are in fact the purposes, and if teamwork is the principal means, of providing medical care. We should seize this time of change as an opportunity to measure and demonstrably improve the contribution of medical documentation and communication to the efficient and long-term remission of disease.

\section{References}

1. Weed LL. Medical records that guide and teach. N Engl J Med. 1968; 278(12):593-600

2. Weed LL. Medical records that guide and teach. N Engl J Med. 1968; 278(12):652-257.

3. Hripcsak G, Vawdrey DK, Fred MR, Bostwick SB. Use of electronic clinical documentation: time spent and team interactions. J Am Med Inform Assoc. 2011;18(2):112-117.

4. Yee T, Needleman J, Pearson M, Parkerton P, Parkerton M, Wolstein J. The influence of integrated electronic medical records and computerized nursing notes on nurses' time spent in documentation. Comput Inform Nurs. 2012;30(6):287-292.

5. Kargul GJ, Wright SM, Knight AM, McNichol MT, Riggio JM. The hybrid progress note: semiautomating daily progress notes to achieve high-quality documentation and improve provider efficiency. Am J Med Qual. 2013;28(1):25-32. 
6. Stetson PD, Morrison FP, Bakken S, Johnson SB. Preliminary development of the physician documentation quality instrument. J Am Med Inform Assoc. 2008;15(4):534-541.

7. Deering S, Poggi S, Hodor J, Macedonia C, Satin AJ. Evaluation of residents' delivery notes after a simulated shoulder dystocia. Obstet Gynecol. 2004;104(4):667-670.

8. Park YS, Lineberry M, Hyderi A, Bordage G, Riddle J, Yudkowsky R. Validity evidence for a patient note scoring rubric based on the new patient note format of the United States Medical Licensing Examination. Acad Med. 2013;88(10):1552-1557.

9. Hanson JL, Stephens MB, Pangaro LN, Gimbel RW. Quality of outpatient clinical notes: a stakeholder definition derived through qualitative research. BMC Health Serv Res. 2012;12:407.

10. Hayrinen K, Saranto K, Nykanen P. Definition, structure, content, use and impacts of electronic health records: a review of the research literature. Int J Med Inform. 2008;77(5):291-304.

11. Grigg E, Palmer A, Grigg J, et al. Randomised trial comparing the recording ability of a novel, electronic emergency documentation system with the AHA paper cardiac arrest record [published online ahead of print July 29, 2013]. Emerg Med J. doi: 10.1136/emermed-2013202512.
12. Rosenbloom ST, Stead WW, Denny JC, et al. Generating clinical notes for electronic health record systems. Appl Clin Inform. 2010;1(3): 232-243.

13. Park SY, Lee SY, Chen Y. The effects of EMR deployment on doctors' work practices: a qualitative study in the emergency department of a teaching hospital. Int J Med Inform. 2012;81(3):204-217.

14. Stengel D, Bauwens K, Walter M, Kopfer T, Ekkernkamp A. Comparison of handheld computer-assisted and conventional paper chart documentation of medical records. A randomized, controlled trial. J Bone Joint Surg Am. 2004;86A(3):553-560.

15. Rao P, Andrei A, Fried A, Gonzalez D, Shine D. Assessing quality and efficiency of discharge summaries. Am J Med Qual. 2005;20(6):337-343.

16. O'Donnell HC, Kaushal R, Barron Y, Callahan MA, Adelman RD, Siegler EL. Physicians' attitudes towards copy and pasting in electronic note writing. J Gen Intern Med. 2009;24(1):63-68.

17. Shoolin J, Ozeran L, Hamann C, Bria Ii W. Association of medical directors of information systems consensus on inpatient electronic health record documentation. Appl Clin Inform. 2013;4(2):293-303.

18. Linder JA, Schnipper JL, Middleton BJ. Method of electronic health record documentation and quality of primary care. Am Med Inform Assoc. 2012;19(6):1019-1024. 